Essays, opinions, and professional judgments are welcome in this section of AJE. Forum articles speak to and about the philosophical, ethical, and practical dilemmas of our profession. Authors are invited to express their views to encourage constructive dialogue centered on issues. To keep the dialogue substantive, other articles motivated by previous Forum presentations should have independent titles and themes. Items labeled "Comments on ..." and "Rejoinder to ..." will not be published in Forum-such responses are welcome and encouraged in the In Response section of AJE. Standard citations and reference lists should acknowledge and identify earlier contributions and viewpoints. Manuscripts should not exceed 10 double-spaced typewritten pages in length, unless the paper is invited by the editor.

The views expressed in this section are independent of and not necessarily shared by AJE editors. By design, "Forums" are open to diverse views, in the hope that such diversity will enhance professional dialogue.

\title{
Effective Use and Misuse of Performance Measurement
}

\author{
BURT PERRIN
}

\begin{abstract}
Performance measurement (PM) is all the rage. It is widely touted as the new way of providing for a focus on the results of public programs. But in the current discussion about PM, there is little recognition of previous PM attempts, which failed to live up to their

Burt Perrin billing. This article identifies fallacies in the logic of PM and provides examples of ways in which PM is routinely misused. As a result, performance measures are frequently irrelevant-or worse. Used in isolation, they invariably reward and encourage the wrong activities and result in less, rather than more, attention to outcome and quality. This article also identifies strategies for effective use of PMs. In particular, it identifies how PMs can be useful for monitoring purposes, for raising questions, and for identifying areas requiring management attention. PMs, by themselves, are not appropriate for assessing outcomes, for determining future directions or for resource allocation. They can, however, be one important component of a comprehensive evaluation strategy.
\end{abstract}

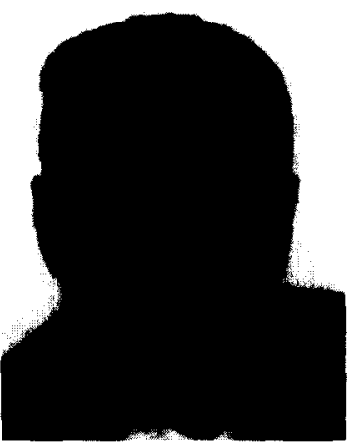

Burt Perrin - 99 Rose Park Drive, Toronto, Ontario M4T 1R3, Canada; Tel: (416) 486-4666; Fax: (416) 486-4665; E-Mail: Burt_Perrin@Compuserve.com. Address will change in April 1999 to: 30770 Vissec, France; Tel: +33 4.67.81.50.11.

American Journal of Evaluation, Vol. 19, No. 3, 1998, pp. 367-379.

All rights of reproduction in any form reserved. ISSN: $1098-2140$ Copyright $\odot 1998$ by American Evaluation Association. 


\section{BACKGROUND AND HISTORY TO PERFORMANCE MEASUREMENT}

"In Poland under communism, the performance of furniture factories was measured in the tonnes of furniture shipped. As a result, Poland now has the heaviest furniture on the planet."1

Performance measurement (PM) is widely touted as the new way to ensure a focus on results and accountability, to finally determine what publicly funded programs are up to, and to provide for control over expenditures. Performance measurement systems are currently being implemented, and sometimes even built into legislative requirements, by governments across the English speaking world.

Is PM the silver bullet its advocates claim it to be? In fact, there is increasing evidence that it does not live up to its billing. Despite claims about the newness of PM, there is nothing new about it. As Winston (1997) has pointed out, the only thing new about "performance measurement" is its name. PM "reforms" have been recycled since the 1960 s.

In the current discussion about PM, there is almost no reference to similar previous systems, such as Management by Objectives (MBO), Program Planning and Budgeting Systems (PPBS), and Management by Results (MBR), which were in widespread use in the 1970s and early 80 s. These systems slowly disappeared when it became apparent that they were not serving their intended purposes. As Winston (1997) indicates, we seem to have lost our corporate memory. Many of those who were involved with former approaches to PM have moved on to other positions, or seem to have forgotten why these systems fell out of favor.

Without taking into account past experience with similar approaches, and without critical examination and evaluation of current approaches to PM, the current fascination with PM runs the risk of being just another management fad which too shall pass in the course of time. Lack of acknowledgement of earlier approaches precludes the opportunity to learn from and to build upon past experiences.

There is increasing evidence that current approaches to PM are repeating the mistakes of the past. Mintzberg (1994), in his influential book The Rise and Fall of Strategic Planning, has pointed to the failure of PM systems, in Canada and elsewhere in both the public and private sectors. He indicates that these and similar measurement-based approaches have not resulted in improved periormance or a focus on outcomes. On the contrary, they have hampered the development and implementation of effective strategy. Wildavsky (1974) stated that: "PPBS has failed everywhere and at all times." Others (e.g., Winston, 1993; Perrin, 1997; Schick, 1973) similarly have pointed out the failures of past approaches to PM. The infamous Vietnam body counts, which used counts of "enemy" dead as an indicator of progress in fighting the war, still remain as the classic example illustrating how a PM approach can result in horrible distortions. As Mintzberg (1996a) says: "How many times do we have to come back to this one until we give up?"

The Vietnam body counts result from the introduction of PPBS in the U.S. Defense Department, Robert McNamara's attempt to introduce private sector management techniques to the public sector. Performance measurement systems may be more appropriate in the private sector, where outcomes can usually be expressed in terms of dollars or other countable units. But ironically, even in the private sector there is increasing evidence of the limitations of PM which focus too narrowly on outcome and short-term financial indicators.

For example, Mintzberg (1994) describes how performance management has failed private as well as public sector organizations. W. Edward Deming, the father of Total Quality 
Management and Statistical Process Control (SPC), is frequently misunderstood and miscited as a supporter of performance management techniques. In fact, he was strongly opposed to such practices, stating for example: "Focus on outcome (management by numbers, MBO, work standards, met specifications, zero defects, appraisal of performance) must be abolished, leadership put in its place. (Deming, 1986)" Handy (1996) says that traditional measurement systems, "conditioned by the philosophy of the audit . . to count only what they can put their finger on and cross their hearts about" results in more attention to efficiency than effectiveness and to lack of attention to what is really important, even if difficult to quantify, such as a business's intellectual assets and how it is positioned to respond to the future.

For the above and other reasons, the private sector is moving away from a narrow measurement focus on outcomes towards a broader approach (e.g., the "balanced scorecard" of Kaplan and Norton, 1992) which looks at a wide range of measures, including difficult-to-measure factors such as focus on innovation and learning. Recent evidence from the United Kingdom (Ruddle and Feeny, 1997, cited in Houlder, 1997) indicates that companies that focus their measurement systems on traditional short-term financial targets are less effective than those which look at broader, hard-to-measure issues such as employee behavior, skills and infrastructure. In other words, organizations that focus on quantifiable measures of outcome are less effective at achieving their desired outcomes than those that take a broader perspective!

My own experience with performance measurement, first in government and then as a consultant and advisor, coincided with at least two go-rounds of performance measurement. I was initially a strong supporter and advocate of performance measurement, because of my interest in instilling a focus on outcomes, rather than just on activities. Being preoccupied with activities was (and is!) all too common in many public service programs. My interest subsequently tumed to disillusionment and then to ambivalence after I witnessed how performance measurement actually worked in practice.

I joined the Ontario government in the 1970s, at the time its performance measurement system, Management by Results (MBR), was being introduced. I was involved in one of the first MBR pilots, and subsequently was MBR coordinator in a line Division. I worked extensively with a variety of program managers and coordinators, assisting and, at times, cajoling them into thinking in outcome terms and in coming up with results measures for their programs. I was able to help some individuals think more in terms of outcome. I tried to make MBR work in my area, and my experience probably was more positive than most.

The reality, however, was that MBR was essentially a paper exercise. MBR plans and reports bore little relationship to what was really going on. They were largely irrelevant to management. The requirement that indicators be quantitative, with progress reported quarterly, led to widespread use of easy-to-count indicators which often had little or no relationship to what the program was supposed to be doing. For example, a colleague working in a commission responsible for regulating land use planning and development recalled how they used numbers of subdivisions approved as their primary outcome indicator. "Results" indicators often were really measures of activities, peripheral to what the program was supposed to be doing, chosen because they were the easiest to quantify. MBR reports at the program level were largely irrelevant. The "rollups", which merged the "results" of many disparate programs onto a single form, often on a single page to make it simple for senior managers to review, were usually totally devoid of meaning.

I left government in the mid 1980s. MBR was eventually left to die. Now an entirely new performance measurement system has been introduced, with no reference to MBR and with few people remaining who seem to remember it. MBR's greatest damage probably was lack 
of use, along with the resultant waste of staff time and resources. In some cases, managers may have developed a better appreciation of the differences between activities, outputs and outcomes, and the need to manage for outcomes. But probably the most common legacy was increased cynicism about measurement, and resistance to other forms of evaluation.

Most line managers were aware of the limitations of MBR. But occasionally staff in positions with limited direct contact with line programs actually believed that MBR reports represented some form of reality. To the extent that these individuals influenced the decisionmaking process, MBR data actually reduced the appropriateness of actions which wcrc taken.

\section{Some Inherent Flaws and Limitations in the Use of Performance Indicators to Ascertain Program Performance}

A key question remains: are the limitations of performance measurement due to its faulty use-e.g. poor performance indicators (PIs), or a result of more basic flaws in its logic? There is convincing evidence supporting the latter interpretation. I briefly discuss eight of these problems and limitations below.

1. Varying Interpretations of the "Same" Terms and Concepts. PIs, no matter how clearly described, are invariably used, recorded and interpreted in varying ways. Thus there can be a lack of comparability across different sites and staff, even with a seemingly straightforward measure such as the numbers of clients served. For example, what is "a client" in a community mental health program? Is it anyone who phones or walks in the door and who receives some sort of response, even if this is just a referral to someplace else? Or is it someone who has been screened and subsequently has a file opened? If the same individual is enrolled in more than one program offered by the same agency, is s/he counted as one or multiple clients? What if the same person is enrolled in different agencies within the same "system," e.g., different mental health services in the same community? If a person leaves or is discharged and then returns, is s/he counted as one-or two (or more) clients? I have witnessed programs defining "client" in all the above ways, sometimes with the purpose of aggregating these numbers. Other measures (e.g., "crisis," "follow up") are even more likely to be interpreted - and recorded and reported-in varying and frequently inconsistent ways.

I recently interviewed court clerks in a number of courthouses about how they go about recording their statistics. It became apparent that measures such as "inquiries," "cases involving child support," "applicants with (or without) legal representation," and "judicial orders" were counted in varying, often inconsistent ways, at different courthouses and even by different staff working side by side. As a result, aggregated statistics about court workload and outcomes based upon these reports are meaningless at best-although they have not been treated this way by senior management who apparently are unaware that these "straightforward" terms are anything but!

Problems such as the above can be minimized by recognizing that virtually any measure can be interpreted in various ways, by pretesting measures to identify how they may be interpreted in the field, and by providing clear and unambiguous definitions. Training and orientation also helps in leading to common interpretations, as does the active involvement of the staff who will be responsible for recording the information. Bottom-up approaches that allow staff to understand the purpose of the information collection and to feel some ownership in the measures which are developed invariably result in more accurate, consistent and meaningful information than the more common top-down approach. 
While techniques such as these help in enhancing the accuracy of statistics, they have limitations and are not always feasible. This is particularly the case when common measures are applied across a number of different agencies or even different settings within the same organizations. For example, codebooks that provide specific definitions are often difficult for busy front-line staff to internalize (I have yet to meet a front-line staff who does not feel busy and overworked); as a result, they are routinely ignored. It is difficult to involve staff in diverse and geographically dispersed settings in the development of a common reporting framework and when this is done, it inevitably involves managers rather than front-line staff. Given staff turnover, the orientation, training and monitoring process regarding compilation of indicators needs to be never ending to ensure quality control.

As discussed in a later section, when staff feel that the future of their program or even their own jobs may be dependent upon making the numbers look good, they inevitably will interpret definitions in a way that is most favorable to the agency. For example, Canada has employment equity legislation requiring federally regulated industries to develop and implement plans for equity in the employment of disadvantaged groups, including women, visible minorities, aboriginal people, and people with disabilities. One bank showed strong improvement in its record of employment of people with disabilities - until a legal center representing the rights of people with disabilities grew suspicious and, upon investigation, discovered that the bank selectively changed its definition of disability to include a broader range of people, such as those requiring eyeglasses, as disabled, thus increasing their numbers.

2. Goal Displacement. When indicators become the objective, they result in "goal displacement," which leads to emphasis on the wrong activities and encourages creaming and other means of "making the numbers" without improving actual outcomes. As a result, they frequently distort the direction of programs, diverting attention away from, rather than towards, what the program should be doing. Less, rather than more, attention is paid to outcomes and as Davies (1997) has indicated: "People work to the indicators and spend increasing amounts of time generating accountability information, usually to the detriment of the program."

Goal displacement is most likely when consequences rest upon a program's performance in "meeting its numbers." Both critics (e.g., Campbell, 1988) and supporters (e.g., Osborne and Gaebler (1992) of PM have indicated that corruption of PIs, via creaming and other means, is almost inevitable under such circumstances. Yet the trend in North America is towards building PIs into performance contracts of managers, and even into legislation.

Heavy Polish furniture and the Vietnam body counts, mentioned earlier, serve as classic examples of the perverse consequences of goal displacement. Another example, headlined in a Toronto newspaper: "13-year officer wrote phony tickets," refers to a police officer who was recently convicted for fabricating reports of traffic violations in what the judge described as "a crime that makes no sense at all." But the officer in question was near the top of his platoon for issuing tickets.

Canada's new Employment Insurance Act provides two "primary measures" for assessing the effectiveness of employment programs: clients obtaining jobs and savings to the employment insurance fund. One can hardly quarrel with these as overall goals. But when the performance of programs and staff are based upon these criteria, goal displacement is almost inevitable, manifested through a focus on the less needy clients (i.e., creaming), and through selectively defining "employment" to include part time or temporary jobs or self employment as well as full-time work. There is evidence (e.g., Perrin, 1996) of this happening, such as 
employment centres placing a low priority on serving people with disabilities who have the greatest need for assistance in obtaining employment.

3. Use of Meaningless and Irrelevant Measures. PIs frequently do not reflect what is really occurring for many different reasons. As Sir Josiah Stamp is said to have observed:

The Government is very keen on amassing statistics. They collect them, add them, raise them to the nth power, take the cube root and prepare wonderful diagrams. But you must never forget that every one of these figures comes in the first instance from the village watchman, who just puts down what he pleases (cited by Smith, 1989).

Two recent incidents attest to the veracity of this statement. The first was the following statement in a draft report of a national U.S. literacy organization: "Adult literacy practitioners are so overworked, underfunded and overregulated that many burn out and quit, while others 'fudge' their performance figures." The second was my own recent experience, when I visited a number of court houses and met with clerks who pointed out to me how impossible it was to collect the information required for their reports. When I asked how they compile and submit their weekly statistics, I was told that: "We put down something that sounds reasonable."

Such situations should come as no surprise to anyone who has spent significant time in the field. But people such as some head office staff, senior managers, and even some evaluators removed from the realities of how things often work at the front lines often believe "the numbers," which have a seductive reality by their (false) precision.

PIs can be irrelevant, even if they are accurate. The essence of PM is to reduce a complex program to a small number of indicators. This, however, is inconsistent with systems theory and other sources that recognize that the whole is greater than the sum of its parts. PIs ignore the inherent complexities of social phenomena, which involve many interacting factors that cannot meaningfully be reduced to one or a finite number of quantitative indicators. Attempting to reduce a complex program or social intervention, such as initiatives in child welfare, economic development, or health promotion, to a small number of quantitative indicators can disguise and mislead rather than inform what is really happening. Thus PIs can confuse performance "indicators" with the underlying reality.

As Newcomer (1997b) indicates: "Defining performance is an inherently political process." The danger of indicators representing a particular perspective is enhanced when only a small number of indicators are used to supposedly reflect the outcomes of a complex undertaking. I have been told by funders and others that they could selectively choose indicators that could make almost any program look good-or bad.

There is an inverse relationship between the importance of an indicator and the ease, or even possibility, of its quantification. As Patton (1997b) has indicated: "To require goals to be clear, specific and measurable is to require programs to attempt only those things that social scientists know how to measure." Deming (1986) said that: "One cannot be successful on visible figures alone.... The most important figures that one needs for management are unknown or unknowable." Many activities in the public policy realm, by their very nature, are complex and intangible and cannot be reduced to a numerical figure. As Mintzberg (1996a) stated: "Assessment of many of the most common activities in government requires soft judgmentsomething that hard measurement cannot provide.... Measurement often misse[s] the point, sometimes causing awful distortions." 
The above discussion emphasizes that what is measured, or even measurable, often bears little resemblance to what is relevant. This certainly reflects my experience with MBR when I was in government.

4. Cost Savings vs. Cost Shifting. PIs typically look at individual programs out of context, ignoring inter-relationships and the reality that few programs do-or should-act in isolation. Consequently, "outcomes" may represent cost shifting rather than true cost savings, ignoring or transferring needs and clients elsewhere rather than actually addressing these.

For example, program "exits" is a common indicator of the success of welfare programs. Few systematic attempts, however, are made to discover why people leave welfare, for how long, and where they go. In some cases, individuals are merely transferred from one form of income support program to another. Jurisdictions have been known to pass their clients back and forth, successfully resulting in "exits" in each instance.

For example, accessible transportation is a prerequisite for many people with disabilities if they are to be employed and live independently of social assistance programs. However, there is frequently resistance to providing accessible transportation, as well as other services necessary for people with disabilities to be able to live and work in the community, in part because the financial (and human!) savings occur in a different area from where the costs are incurred.

PIs are invariably short term in nature. But short-term benefits and outcomes may result in future requirements and increased costs over the longer term, thus "shifting" costs into the future.

There has been some recognition of the limitations of indicators that are program specific, for the above and other reasons. A frequent response, however, has been to attempt to hold programs accountable for social indicators that are beyond their own control. Examples include training programs judged by the overall employment rates in their community, or early child intervention programs judged by overall community infant health statistics.

\section{Critical Subgroup Differences Disguised by Misleading Aggregate Indi-} cators. PIs typically obscure subgroup differences. Consequently, the "same" outcome may reflect different forms of program effect. For example, Winston (1993) indicates that a program with 40 percent females can achieve a 60 percent "success" rating, with all-or with noneof the females being successful. This finding would be hidden by an indicator that only looked at the overall success rate.

Similarly, figures of changes in median household income provided by the U.S. Census Bureau for 1996 showed an inflation-adjusted increase in income of 1.2 percent frum the previous year. Not a large increase, but an improvement in the overall income of Americans. A very different picture emerges, however, if one examines income subgroups, for such an analysis reveals that the wealthiest 20 percent saw their income increase 2.2 percent, while for the poorest 20 percent it decreased 1.8 percent. In other words, the inequality gap, which has been widening for years, increased by a further 4 percent in a year when the economy was booming and unemployment falling. This finding would be totally missed by a PI based upon aggregate family income.

6. Limitations of Objective-Based Approaches to Evaluation. PM systems share the well-documented limitations of other objective-based approaches to evaluation. This is onc topic where the "two Michaels", Patton and Scriven, who disagree about many other aspects of evaluation, both agree, with Patton proposing situationally responsive approaches to evaluation, and Scriven the use of goal-free evaluation. There is only space here to mention 
three limitations of the use of objectives for evaluation purposes which are particularly relevant to PM:

- It is difficult to distinguish between the ambitiousness and appropriateness of stated objectives on the one hand, and the actual results achieved on the other. Programs with ambitious objectives that "push the envelope" may be unfairly penalized, while mediocre programs attempting the commonplace are more likely to achieve their objectives;

- Objective-based approaches to evaluation do not take into account unintended or unanticipated effects and consequences, which may be both positive and negative and are frequently more important than the program's stated objectives; and

- Objectives - and PIs - typically are fixed, while the environment, needs and program activities are constantly changing. A responsive program should be changing its objectives and targets. It should be reviewing whether its intended outcomes are still desirable, or need modification, supplementation, or replacement. Objectives and indicators usually should become out of date. Effective programs can be penalized for responding to new needs and opportunities.

7. Useless for Decision Making and Resource Allocation. The most frequently mentioned rationale for performance measurement is to provide for more informed decision making and budgeting (e.g., Hatry, 1997). But PM, by itself, is useless for this purpose. This is a theme emerging from the recent New Directions (Newcomer, 1997a) volume on performance measurement (see especially Hatry, 1997; Joyce, 1997; Newcomer, 1997b; and Plantz, Greenway, and Hendricks, 1997), interestingly in a volume largely supportive of the use of PM for public programs.

As Newcomer (1997b) states: "Performance measurement typically captures quantitative indicators that tell what is occurring with regard to program outputs and perhaps outcomes but, in itself, will not address the how and why questions." For example, a program may fail to meet its performance targets because the program theory is wrong, in which case it should be replaced with something else. But it also may fail to do so for a variety of other reasons such as: inappropriate targets or measures which are not identifying other possible program outcomes; faulty management or implementation, under (or over) funding, unique circumstances (e.g., an employment training program during a recession or when the only employer in a single-industry town closes); the right program in the wrong situation (e.g., effective for some, but not all, of the types of clients it has been serving), measurement of outcomes attempted too soon or at the wrong time, faulty statistics, and so on.

Use of PIs incorrectly assumes causality, inferring that the identified outcomes are a direct result of program activities. As evaluators know, causality can only be assessed through use of an appropriate evaluation design that aims at understanding the "whys" and mechanisms by which outcomes are achieved, and which considers alternative explanations for given results. Winston (1993) gives an Australian example of how a simple indicator of percentage decrease in road accident deaths on a newly redesigned road fails to take into account alternative explanations and unintended consequences.

Thus PIs provide no direct implications for action, unless other means are used to explore the reasons for results and the potential for future impact. Indeed, it is dangerous to make decisions about the future of programs based upon PIs alone, as this is likely to lead to inappropriate action. 
8. Less Focus on Outcome. The sad, supreme irony is that PM systems typically lead to less - rather than more-focus on outcome, on innovation and improvement. As Mintzberg (1996a, 1996b) has indicated, PIs are rooted in a top-down hierarchical "control" model. This emphasis on measurement is inconsistent with other New Public Sector Management objectives of decentralization and delegation of responsibility. A narrow focus on measurement is inconsistent with a focus on change and improvement that requires constant questioning about what else can be done or done better. The end result of judging programs or staff by their "numbers" is not empowerment, critical self-examination, and experimentation with new approaches. Instead, it leads to impaired performance, an emphasis on justifying and defending what was done, and a reluctance to admit that improvement is needed.

When managers and staff are required to collect and compile PM information that is never used (e.g., Joyce, 1997; Patton, 1997a), they can become cynical about PM and also about evaluation. Using measures inappropriately for accountability purposes also leads to cynicism, resistance and attempts to make the numbers look as good as possible.

\section{Strategies for Effective Use of Performance Measures}

Despite the problems and limitations identified above, performance measures still can be useful in selective circumstances, such as serving as one component of a broader, more comprehensive evaluation strategy. I include PIs, where appropriate, in my own evaluation activities, as one of a variety of methods. One should take into account the following factors when considering the use of PIs:

- Recognize that PIs are most appropriate for use in planning and monitoring, not for evaluation. They play an important role in monitoring and in raising questions. They can be invaluable in focusing management attention on issues which require exploration through other informal and/or formal means. In particular, PM can serve as a means of identifying where more comprehensive evaluation approaches would be most useful, and in this way, help in the responsible allocation of resources for evaluation;

- Recognize that every evaluation method, including PM, has limitations which can only be overcome through use of a combination of methods. While this paper has identified flaws and limitations with PM, the same can be said about virtually any other evaluation technique. Few credible evaluations rely upon only a single source of information. It is usually necessary to balance quantitative data from PIs with qualitative forms of information for balance; and

- Be strategic, recognizing that PIs are appropriate for some activities and not for others. Mintzberg (1996a) suggests that some simple and directly delivered services, such as garbage collection, lend themselves to measurement, while strongly cautioning that: "Many activities are in the public sector precisely because of measurement problems: if everything was so crystal clear and every benefit so easily attributable, those activities would have been in the private sector long ago." Hatry (1997) points out that it is very difficult to measure prevention (e.g., of crimes, fires, child abuse, and so on) and that when outcome measures are nevertheless required, non-prevention is measured as a substitute, which sorely misses the point. 


\section{Strategies to Minimize Inappropriate Use of PIs}

The flip side of suggestions for the effective use of PMs (or PIs) is an examination of strategies that will help to reduce their inappropriate use. Six such strategies are discussed briefly in this section.

1. First, be realistic about the context, such as political or organizational requirements for PIs, irrespective of their appropriateness, and help programs work around these realities. It may be helpful to observe the physician's maxim: first, do no harm. Consider who is likely to make use of indicators, identify the potential for misinterpretation, and then develop indicators that are general enough to minimize actual misuse. If possible, identify the types of performance information that could be useful to the people involved with a program and could assist with program improvement. Presentation of findings based upon PIs should be explicit in identifying the limitations of how they should be interpreted, presenting complementary information (e.g., from other forms of evaluation data) whenever possible.

2. Make sure that measurements are at the right level. A logic model can help identify what forms of outcomes may be realistic to expect given the status of the program. Do not hold programs accountable for impacts that are unrealistic, such as using measures of outcome over which a program can only have limited influence, or using measures of impact during the initial stages of a new program, when implementation considerations are more relevant.

3. Always test indicators in advance. In particular, anticipate potential misapplications of measures and test for these, making revisions to preliminary measures and developing strategies to counter these. Recognize that it will take time to get it right. Pretesting is essential, but not sufficient. It will most likely take one or more iterations of actual use to identify how indicators work in practice, to check for accuracy, to confirm the meaningfulness of the data provided, and to make subsequent revisions.

4. Review, revise and update measures frequently. Few measures will be perfect the first time around. Even if they are, they are almost certain to become out of date due to changed needs, circumstances, opportunities and priorities. Measures that remain static are most susceptible to goal displacement. Do not cast measures in stone -or in legislation.

5. Actively involve stakeholders, including program staff and consumers, in developing. reviewing, and revising measures and actively involve them in interpreting findings and identifying implications. Otherwise, there will be no ownership in measures, they are unlikely to be relevant, and they are unlikely to be recorded consistently or accurately. As Wholey and Newcomer (1997) indicate, the personal involvement of senior managers is also critical.

6. Use multiple indicators, in order to examine a variety of program aspects, including process as well as outputs and outcomes. As noted earlier, there is increasing recognition within the private sector of the limitations of measures that focus exclusively on outcomes. It is ironic that the public sector is focusing on outcome measurement when the private sector is moving towards a broader approach.

Many of the chapters in Newcomer (1997a) expand upon the above considerations and add others. One particular theme is worth highlighting. It takes expertise, resources and capac- 
ity to develop and use performance measures. Meaningful measures cannot be developed overnight by managers with little or no experience or training and few or no resources to devote to data collection and analysis. Programs require technical assistance in developing and using measures. Similarly, many funding allocators themselves have little expertise in how to use performance information.

\section{CONCLUSION}

PIs can be useful, in some circumstances, for monitoring purposes. They can help raise questions and identify areas requiring management attention. But they are severely limited in their ability to assess outcomes properly. Used in isolation, they invariably reward and encourage the wrong activities and result in less, rather than more, attention on outcome and quality.

The current wave of performance management tends to ignore previous cycles of performance management, which ended in failure. The evidence indicates that performance measurement, used in isolation, does not provide value for money, does not provide meaningful accountability, and does not as a rule provide accurate outcome information about what is most important. PM is not appropriate for making resource allocation decisions, and generally results in cynicism and resistance to a focus on outcome, effectiveness, and program improvement. As a result, performance management rarely benefits managers or decision makers at any level -or the taxpayers.

But the tragedy is that they frequently appear to do so. Too often, the seduction of numbers take on a life and a reality of their own, even when they are meaningless. Performance measures are almost inevitably subject to misuse, unless the dangers are recognized in advance and controlled for. As Sir Josiah Stamp indicated many years ago, many of the numbers aggregated and analyzed by government bear little resemblance to reality.

For performance measurement to be used effectively: (1) programs need to be provided with adequate resources, including technical expertise, for the effective development of PIs; (2) stakeholders need to be actively involved in the development and use of measures; and (3) considerable time needs to be provided to develop, test, refine, revise and update measures. Unfortunately, many of these conditions are unlikely to be met in the real world, where political realities frequently impose performance measures in a top-down manner, where accountability for results is required in unrealistically short time frames, and where the qualifications accompanying tables or graphs displaying performance indicators are routinely ignored.

Should evaluators be jumping on the PM bandwagon-or do we have a professional responsibility to point out what they can-and cannot do? There are no quick fixes. Complex social programs cannot be reduced to a few easily recorded indicators. Making management decisions based upon such limited and flawed information is a recipe for disaster.

What is the alternative? It is unrealistic to undertake complex evaluation studies as a matter of course. There frequently is a need for greater use of simpler approaches to evaluation, including "quick and dirty" techniques. These can provide information, however crude, required by managers to increase their understanding of what is taking place, and why, and what can help in decisions that will be taken with-or without - definitive information. At the same time, there is need for greater understanding about when to invest in more comprehensive evaluation undertakings. There is a need to understand what types of evaluation can best 
stimulate and reward innovation and experimentation, and as a consequence, result in improved programs. There are no easy answers to these questions.

\section{NOTE}

1. Appeared in the Report on Business, Globe \& Mail (Toronto), about 1996.

\section{REFERENCES}

Campbell, D. T. (1988). The experimenting society. In E. S. Overman (Ed.), Methodology and epistemology for social science, selected papers: D. T. Campbell. Chicago: University of Chicago Press, pp. 290-314.

Davies, I. (1977, June 6). Posting to Govteval (Internet mailing list on evaluation).

Deming, W. E. (1986). Out of the crisis. Cambridge: Massachusetts Institute of Technology Center for Advanced Engineering Study.

Hatry, H. P. (1997). Where the rubber meets the road: Performance measurement for state and local public agencies. In Newcomer, 1997a, 31-44.

Handy, C. (1996). Beyond certainty: The changing worlds of organizations. Boston: Harvard Business School Press.

Houlder, V. (1997, July 18) Wider picture provides the best score. Financial Times, 20.

Joyce, P. G. (1997). Using performance measures for budgeting: A new beat, or is it the same old tune? In Newcomer, 1997a, 45-62.

Kaplan, R. S. \& Norton, D. P. (1992, Jan-Feb). The balanced scorecard: Measures that drive performance. Harvard Business Review, 71-79.

Mintzberg, H. (1994). The rise and fall of strategic planning. New York: The Free Press.

Mintzberg, H. (1996a, May-June). Managing government, governing management. Harvard Business Review, 75-83.

Mintzberg, H. (1996b, July-August). Musings on management. Harvard Business Review, 61-67.

Newcomer, K. (Ed.). (1997a). Using performance measurement to improve public and nonprofit programs. New Directions for Evaluation, Number 75. San Francisco: Jossey-Bass.

Newcomer, K. (1997b). Using performance measurement to improve programs. In Newcomer, 1997a, 5-14.

Osborne, D. \& Gaebler, T. (1992). Reinventing government. New York: Plume.

Patton, M. Q. (1997a). Utilization-focused evaluation: The new century text. Thousand Oaks, CA: Sage Publications Inc.

Patton, M. Q. (1997b, Nov. 8). Utilization-focused evaluation: Conversation with Michael Quinn Patton. Presentation as part of the Presidential Strand, Annual Meeting of the American Evaluation Association, San Diego.

Perrin, B. (1996). Disability and labour market integration: Clarifying federal responsibilities in the evolving social union. In Federal Task Force on Disability Issues, The will to act for Canadians with disabilities: Research papers. Ottawa: Minister of Public Works and Government Services Canada.

Plantz, M. C., Greenway, M. T., \& Hendricks, M. (1997). Outcome measurement: Showing results in the non-profit sector. In Newcomer, 1997a, 15-30.

Ruddle, K. \& Feeny, D. (1997). Transforming the organisation: new approaches to management, measurement and leadership. Oxford: Templeton College Information Centre and Library.

Schick, A. (1973). A death in the bureaucracy: The demise of federal PPB. Public Administrations Review, 33(2), 146-156. 
Smith, M. F. (1989). Evaluability assessment: A practical approach. Boston: Kluwer.

Wholey, J. S. \& Newcomer, K. E. (1997). In Newcomer, 1997a, 91-98.

Wildavsky, A. (1974.) The politics of the budgetary process. 2nd Ed. Boston: Little Brown. (cited by Mintzberg, 1994).

Winston, J. (1993). Performance indicators: Do they perform? Evaluation News and Comment. 2(3), 2229. 